\title{
Development of Solid Lipid Nanoparticles for Praziquantel Delivery: Particle Size Characterization and Cell Toxicity Assessment
}

\author{
A. L. R. SOUZA ${ }^{1,2}$, T. ANDREANI ${ }^{2}$, S. DOKTOROVOVÁ ${ }^{3}$, \\ A. M. SILVA ${ }^{2,4}$, E. B. SOUTO ${ }^{5}$, M. P. D. GREMIÃo ${ }^{1}$ \\ ${ }^{1}$ Department of Pharmaceutical Technology, Faculty of Pharmaceutical Sciences, UNESP, Araraquara, \\ Brazil \\ ${ }^{2}$ Department of Biology and Environment, University of Trás-os-Montes and Alto Douro, Vila Real, Portugal \\ ${ }^{3}$ Centre of Genomics and Biotechnology, IBB/CGB-UTAD, Vila-Real, Portugal \\ ${ }^{4}$ Centre for Research and Technology of Agro-Environmental and Biological Sciences, Vila Real, Portugal \\ ${ }^{5}$ Department of Pharmaceutical Technology, Faculty of Health Sciences, UFP, Porto, Portugal \\ E-mail: analuizars@yahoo.com.br (A. L. R. Souza)
}

Sci Pharm. 2010; 78 : 576

doi:10.3797/scipharm.cespt.8.LNT02

\begin{abstract}
Praziquantel (PZQ) is a drug active against all species of Schistosoma and it is the drug of choice for the treatment of schistosomiasis [1]. Due to its low water solubility and risk of parasite resistance or tolerance to $P Z Q$, it would be useful to develop a novel pharmaceutical product that could increase its therapeutic efficacy and improve the bioavailability. Solid lipid nanoparticles (SLN) combine the advantages of different colloidal carriers and also avoid some of their disadvantages in relation to the stability and possibility of large scale production. Thus, the aim of this work was to develop SLN containing PZQ (SLN-PZQ) and evaluate the cytotoxicity in the HepG2 cell line. The SLN were produced by a modified of the oil-in-water microemulsion method [2] using stearic acid as lipid core and poloxamer 188 as surfactant. The PZQ was incorporated in lipid core for the production of SLN-PZQ. Particle size was measured by dymamic light scattering (DLS) and the electrophoretic mobility was measured by laser Doppler anemometry. The cytotoxicity of PZQ (dissolved in ethanol) and SLN-PZQ was examinated in the HepG2 cell line using AlamarBlue assay [3]. The prepared SLN-PZQ had a mean particle size of $480.4 \mathrm{~nm}$ with a zeta potential of $-36.5 \mathrm{mV}$. In HepG2 cell cultures, the tested SLN-PZQ suggested a decreased toxicity of the drug when delivered by SLN, in comparison to a conventional PZQ solution of similar concentration. The degree of toxicity was shown to be dose-dependent.

This work was supported by CAPES.
\end{abstract}

[1] Cioli D. Chemotherapy of Schistosomiasis: An Update. Parasitol Today. 1998; 14: 418-422. doi:10.1016/S0169-4758(98)01323-4

[2] Heydenreich AV, Westmeier R, Pedersen N, Poulsen HS, Kristensen HG. Preparation and purification of cationic solid lipid nanospheres - effects on particle size, physical stability and cell toxicity. Int $\mathrm{J}$ Pharm. 2003; 254: 83-87. doi:10.1016/S0378-5173(02)00688-9

[3] Miura N, Matsumoto Y, Miyairi S, Nishiyama S, Naganuma A. Protective effects of triterpene compounds against the cytotoxicity of cadmium in HepG2 cells. Mol Pharmacol. 1999; 56: 1324-1328. PMid:10570061 